\title{
STRATEGI KOMUNIKASI PADA POSTER FILM CIN(T)A SEBAGAI DAYA TARIK
}

\author{
Khikmah Susanti dan Duane Masaji Raharja \\ Indraprasta PGRI University, Visual Communication Design, \\ J1 Nangka No. 58 C Tanjung Barat Jagakarsa, Jakarta Selatan, Indonesia \\ soezhan99@gmail.com,duane.raharja@gmail.com
}

\begin{abstract}
Abstrak
Film merupakan media komunikasi massa yang sudah akrab dalam kehidupan masyarakat. Setelah tahun 2000 perkembangan perfilman di Indonesia mulai bangkit lagi. Film bergenre drama percintaan mendominasi, salah satunya, cin(T)a. Dalam dunia industri perfilman, poster merupakan bagian yang erat hubungannya dengan film. Dalam hal ini penulisan pada poster film cin(T)a menggunakan susunan huruf dan tanda baca yang berbeda dari biasanya. Ini yang akan menjadi pokok bahasan dalam artikel ini.
\end{abstract}

Keywords: Poster, Film, Iklan, Penulisan.

\section{Abstract}

Film is a medium of mass communication that is familiar in people's lives. After 2000 the development of film industry in Indonesia began to rise again. Romance drama film genre dominates, one of which is $\operatorname{cin}(T) a$. In the world of the film industry, the poster is part of a close relationship with the film. In this case the writing on the movie poster cin(T)a use arrangement of letters and punctuation differently than usual. It will be the subject of this article. 


\section{PENDAHULUAN}

Film merupakan media komunikasi massa yang sudah akrab dalam kehidupan masyarakat di era serba digital sekarang ini (pasca tahun 2000). Menurut UU nomor 33 tahun 2009, "Film adalah karya seni budaya yang merupakan pranata sosial dan media komunikasi massa yang dibuat berdasarkan kaidah sinematografi dengan atau tanpa suara dan dapat dipertunjukkan". Masih berdasarkan UU nomor 33 tahun 2009, secara garis besar disebutkan film sebagai media komunikasi massa merupakan sarana untuk mencerdaskan kehidupan bangsa, pengembangan potensi diri, pembinaan akhlak mulia, pemajuan kesejahteraan masyarakat, serta wahana promosi Indonesia di dunia internasional.

$$
\text { Setelah tahun } 2000
$$

perkembangan perfilman di Indonesia mulai bangkit lagi. Dengan munculnya beberapa produksi film karya anak bangsa. Salah satunya film Ada Apa Dengan Cinta. Film ini disebut-sebut sebagai tanda kebangkitan perfilman Indonesia. Berkisah tentang kehidupan dua remaja yang pada akhirnya saling jatuh cinta, setelah mengalami hubungan yang rumit dan penuh dengan konflik.

Selain film Ada Apa Dengan Cinta, film ber-genre drama percintaan lainnya adalah film $\operatorname{cin}(\mathrm{T}) \mathrm{a}$, film $\operatorname{cin}(\mathrm{T}) \mathrm{a}$ masuk ke dalam daftar dari Top10 Indo tentang 10 film romantis Indonesia terbaik. Film $\operatorname{cin}(\mathrm{T}) \mathrm{a}$ telah meraih penghargaan piala citra pada festival film indonesia ( FFI ) 2009 dengan kategori penulis skenario cerita asli terbaik. Selain itu film ini juga mendapat penghargaan di Jakarta international film festival sebagai "The Most Wanted Indonesian Movie". Film ini juga menjadi film pembuka pekan festival film tionghoa Indonesia (PFFTI).
Tema percintaan yang diangkat pada film ini adalah konflik tentang perbedaan ras. Mahasiswa etnis batak keturunan cina dan mahasiswa asal jawa yang saling mencintai namun terbentur oleh tembok perbedaan etnis seperti agama, tradisi, dan prinsip hidup. Tak hanya tentang cinta, film cin(T)a juga menggambarkan tentang toleransi beragama dan kecintaan kepada sang pencipta. Mengingat penduduk Indonesia adalah Negara yang plural, punya berbagai macam suku, bahasa dan agama.

Film bergenre drama percintaan mampu memikat banyak penonton. Penonton terasa terbawa alur cerita dan terasa diaduk-aduk emosinya bahkan sampai meneteskan air mata, ketika menyaksikan film drama percintaan tersebut. Tema percintaan memang sebuah tema yang sangat dekat dengan kehidupan masyarakat sehari-hari. Cinta merupakan rasa yang ada pada diri tiap manusia. Cinta dengan yang maha Pencipta, orang tua, guru, sahabat, dan kekasih.

Dalam dunia industri perfilman, poster merupakan bagian yang erat hubungannya dengan film. Film dan poster, merupakan dua bagian yang sulit untuk dipisahkan layaknya dua sisi mata uang. Keduanya saling berkaitan satu sama lain. Poster adalah sebagai kombinasi visual dari rancangan yang kuat, dengan warna, dan pesan dengan maksud untuk menangkap perhatian orang yang lewat tetapi cukup lama menanamkan gagasan yang berarti di dalam ingatannya (Nana Sudjana dan Ahmad Rivai, 2010: 51). Poster dirancang dan dibuat untuk menunjang kegiatan publikasi dari film yang telah ada. Tujuannya untuk menarik perhatian khalayak agar menyaksikan film tersebut.

Pengaplikasian poster dengan ditempel di dinding atau permukaan datar lainnya dengan sifat mencari perhatian mata sekuat mungkin. Karena itu poster 
biasanya dibuat dengan warna-warna kontras dan kuat. Poster bisa menjadi sarana iklan, pendidikan, propaganda, sosialisasi dan dekorasi. Dan keberadaan poster sangat penting untuk menunjang industri perfilman dalam mempromosikan film-filmnya. Agar film tersebut dapat diketahui oleh masyarakat luas.

Media poster film adalah media yang efektif dalam sebuah proses komunikasi visual, karena sebuah poster mempunyai nilai efektifitas tersendiri dengan fungsi dan karakter tersendiri. Dewasa ini media komunikasi yang digunakan oleh manusia sangat beragam, dan tidak menutup kemungkinan ke depannya akan terus berinovasi dan bertambah. Media komunikasi digunakan untuk tercapainya tujuan komunikasi.

Tak hanya elemen ilustrasi, penggunaan tanda baca dan penulisan huruf pun turut mempercantik visualisasi poster film cin(T)a. Penulisan merupakan proses, cara, perbuatan menulis atau menuliskan suatu gagasan atau pikiran kedalam bentuk tulisan. Sebuah komunikasi menengah yang mewakili Bahasa melalui penjelasan dari tanda dan simbol. Dalam kebanyakan bahasa, penulisan adalah pelengkap berbicara atau bahasa berbicara.

Poster sebagaimana fungsinya, perlu memiliki kriteria sebagai berikut (Supriyono, 2010): (a) Mampu menarik perhatian, (b) Berhasil menyampaikan informasi secara cepat, (c) Mampu meyakinkan, mempengaruhi, dan membentuk opini, (d) Menggunakan warnawarna mengesankan, (e) Sederhana.

Pada poster film cin(T)a terlihat upaya untuk memenuhi kriteria tersebut, yaitu pada kriteria (a), (c) dan (e) yaitu mampu menarik perhatian, meyakinkan, mempengaruhi, dan membentuk opini dengan memberi kesan sederhana. Dalam hal ini terletak pada penulisan judul film. Dengan menggunakan susunan huruf dan tanda baca yang berbeda dari biasanya.
Ini yang akan menjadi pokok bahasan dalam penelitian ini.

\section{METODE}

Pada penelitian ini digunakan metode studi deskriptif kualitatif. Dimana peneliti berusaha menggambarkan suatu gejala sosial. Dengan kata lain penelitian ini bertujuan untuk menggambarkan sifat sesuatu yang tengah berlangsung pada saat studi. Penelitian ini berusaha untuk menuturkan dan menafsirkan data yang ada, misalnya tentang situasi yang dialami, satu hubungan, kegiatan, pandangan, sikap yang menampak, atau tentang satu proses yang sedang berlangsung, pengaruh yang sedang bekerja, kelainan yang sedang muncul, kecenderungan yang menampak, pertentangan yang meruncing, dan sebagainya.

Pada poster film cin(T)a terlihat upaya untuk memenuhi kriteria sebuah poster, yaitu pada kriteria (a), (c) dan (e) yaitu mampu menarik perhatian, meyakinkan, mempengaruhi, dan membentuk opini dengan memberi kesan sederhana. Dalam hal ini terletak pada penulisan judul film. Dengan menggunakan susunan huruf dan tanda baca yang berbeda dari biasanya. Ini yang akan menjadi pokok bahasan dalam penelitian ini.

\section{PEMBAHASAN}

Dunia perfilman yang semakin menunjukkan eksistensinya, tak luput dari keberadaan poster yang menunjang kepopuleran film tersebut. Poster sebagai media komunikasi yang terdapat penyampaian pesan melalui visualisasi yang terdapat di dalamnya.

Margono Sastrosoediro dalam bukunya Poster Layanan Masyarakat dan Generasi Muda berdasarkan tujuan 
periklanannya menjelaskan, poster dibagi menjadi 2 macam yaitu:

1. Poster Komersial.

Poster Komersial adalah poster yang memiliki tujuan untuk mengkampanyekan suatu brand produk dagang untuk meningkatkan volume penjualan dan pemasaran itu sendiri.

2. Poster Non Komersial atau Sosial.

Poster Non Komersial atau Sosial adalah poster yang memiliki tujuan untuk melayani kepentingan umum bersifat sosial kemasyarakatan. Dasarnya adalah sarana penyampaian atau informasi yang bersifat sosial.

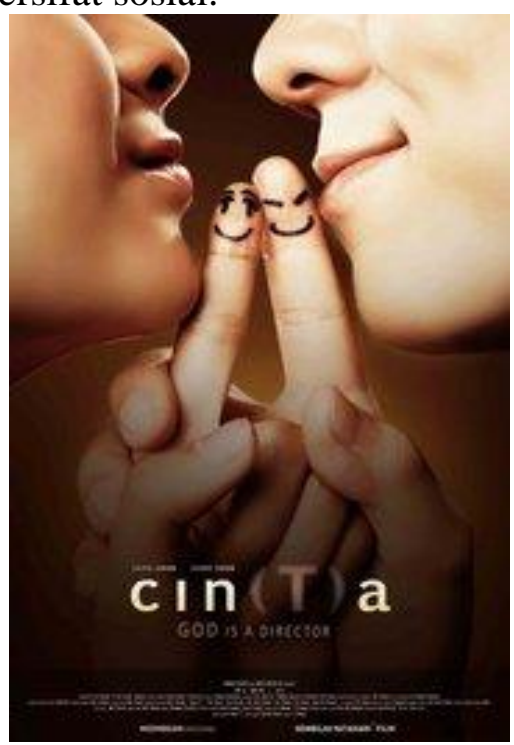

Figure 1: Poster Film cin(T)a

Poster pada film cin(T)a adalah contoh dari poster komersial, karena poster film memiliki tujuan untuk mempromosikan dan mempopulerkan film yang telah diproduksi untuk dapat dinikmati oleh masyarakat luas.

Selanjutnya menurut Margono Sastrosoediro, Dalam mendesain suatu poster perlu diperhatikan beberapa hal berikut :

1. Poster harus dapat dibaca dan pesannya dapat dimengerti.

2. Menimbulkan sifat menarik dan harus mengandung sesuatu yang baru dalam bentuk maupun dalam pesan yang tertulis.

3. Poster harus didesain dalam bentuk yang cukup besar bila dilihat dari jarak jauh agar mem bawa hasil seperti yang dinginkan.

4. Poster dari jarak dekat harus memberikan gairah dengan memakai pengenalan yang mudah dan detail yang menyenangkan.

5. Poster harus tetap di dalam ingatan penonton dengan mengadakan kontak baru antara penonton dan sebuah topik baru atau sebuah hasil baru.

Dapat disimpulkan pada poster cin(T)a sudah memperhatikan hal-hal di atas, khususnya sebuah poster harus tetap di dalam ingatan penonton dengan mengadakan kontak baru antara penonton dan sebuah topik baru atau sebuah hasil baru.

\section{Penggunaan Tanda baca}

Pada poster film cin(T)a. Terdapat tanda baca kurung ( ). Yang digunakan untuk memisahkan huruf $\mathrm{T}$ yang ditulis secara capital.

Menurut peraturan Menteri Pendidikan Nasioanl Republik Indonesia Nomor 46 Tahun 2009 Tentang Pedoman Umum Ejaan Bahasa Indonesia yang disempurnakan. Penggunaan tanda baca kurung :

1. Tanda kurung dipakai untuk mengapit tambahan keterangan atau penjelasan.

2. Tanda kurung dipakai untuk mengapit keterangan atau penjelasan yang bukan bagian utama kalimat.

3. Tanda kurung dipakai untuk mengapit huruf yang kehadirannya di dalam teks dapat dihilangkan.

4. Tanda kurung dipakai untuk mengapit angka atau huruf yang memerinci urutan keterangan.

Poster film cin(T)a, menggunakan tanda kurung tersebut untuk mengapit huruf yang kehadirannya di dalam teks dapat dihilangkan. Jika huruf $\mathrm{T}$ nya 
dihilangkan maka akan terbaca cina, selain mengartikan nama sebuah Negara. Cina merupakan nama aktor pria pada film cin(T)a. Yang diceritakan di film tersebut sebagai pria yang berasal dari suku tionghoa yang tinggal di daerah Sumatera Utara. Dia bercita-cita untuk menjadi seorang Gubernur Tapanuli ketika kelak Tapanuli berdiri sendiri menjadi sebuah provinsi. Huruf A untuk Annisa nama aktris wanita. Muslim keturunan jawa, seorang bintang film yang rajin beribadah.

Sedangkan penulisan capital pada huruf $\mathrm{T}$ ada makna yang ingin disampaikan oleh sang sutradara, huruf kapital $\mathrm{T}$ dalam kurung mempunyai makna Tuhan. Dan judul film ini dapat diartikan cinta antara Cina, Tuhan dan Annisa. Cin untuk Cina, A untuk Annisa, (T) untuk the third character. Ada yang manggil Tuhan, Theis, Theo, TheOne, TheAlmighty, dll.

Dari keterangan di atas, judul dari film $\operatorname{cin}(\mathrm{T}) \mathrm{a}$ ini dapat disimpulkan cinta sesama makhluk dan cinta terhadap Tuhannya. Betapa besar rasa cinta terhadap sesama manusia tidak akan bisa mengalahkan cinta mahkluk terhadap Tuhannya. Cinta makhluk kepada Tuhan haruslah di atas segalanya melebihi cinta kepada sesama makhluk. (T) untuk Tuhan adalah karakter yang tidak bisa digambarkan tetapi bisa dirasakan kehadiranNya dengan melihat semua ciptaanNya.

\section{Elemen-Elemen Dalam Poster dan Penulisan Judul}

Menurut Askurifai Baksin, elemen-elemen yang harus ada pada poster film antara lain adalah (1) Ilustrasi,

(2) Tagline, (3) Kredit Titel (credit title),

(4) Tipografi. Keempat elemen tersebut dikombinasikan agar khalayak merasa tertarik dengan produk film tersebut. Dari keempat elemen, dapat dipahami bahwa terdapat dua elemen visual, dan dua lainnya lebih merujuk ke elemen komunikasi.

Pada poster film cin(T)a sudah memiliki keempat elemen tersebut. Dengan menggunakan gambar serang wanita dan pria. Tagline pada poster film tersebut adalah "God is A Director". Dan juga terdapat credit title, serta terdapat tipografi. Jadi poster film cin(T)a sudah menggunakan empat elemen yang harus ada dalam poster film.

Pembahasan penulisan pada poster film cin(T)a, menjadi sesuatu yang menarik untuk menjadi bahasan dalam penelitian ini. Apa yang pertama kali barusan seseorang lihat sebelum mulai mengetahui dan menyaksikan sebuah film? Pasti judulnya! Kemungkinan kecil ada orang yang menyaksikan sebuah film tanpa membaca judulnya terlebih dahulu. Judul biasanya berupa sebuah kata atau kalimat yang singkat, namum memiliki peranan yang penting. Bayangkan, ketika kita sudah membuat sebuah fil yang menghabiskan banyak sumber daya materil maupun non-materil. Kemudian judulnya dibuat secara asal-asalan, sehingga hanya sedikit yang tertarik menyaksikan film tersebut.

Pembahasan pada penulisan judul poster fil cin(T)a, juga berkaitan atau mengacu pada prinsip tipografi, yaitu kualitas pada huruf yang membuat huruf tersebut dapat terbaca (legibility), kualitas pada teks yang membuat teks tersebut mudah dibaca (readability), kemampuan huruf dan teks yang dapat dibaca dalam jarak tertentu (visibility), serta kualitas pada huruf dan teks untuk dapat dimengerti dengan jelas (clarity).

Pada poster film cin(T)a, sudah mengacu pada legibility, yaitu judul film pada poster dapat terbaca, warna kuning dengan background warna agak gelap seperti warna kecoklatan sehingga judul film tersebut menjadi mudah terbaca. Untuk prinsip readibility, ruang yang diberikan untuk penempatan judul sangat 
luas, susunan hurufnya pun tidak terlalu dekat antara huruf yang satu dengan yang lain, meskipun pada tanda baca dan huruf $\mathrm{T}$ dibuat capital, tidak tebal, dan dibuat sedikit blur namun tetap mudah terbaca. Untuk visibility, pada judul film cin(T)a teksnya dapat terbaca dalam jarak pandang enam meter, penggunaan warna dan font pada judul masih dapat terbaca dengan baik. Dan pada prinsip clarity kualitas pada huruf dan teks pada judul film di poster cin(T)a dapat dimengerti dengan jelas, karena memang hanya terdapat satu kalimat yaitu cinta, sehingga bagi yang membacanya sudah pasti dapat mengerti arti dari kalimat tersebut. Pada judul film cinta tidak begitu banyak menampilkan efek visual, hanya pada tanda baca dan huruf $\mathrm{T}$ dibuat sedikit blur, dapat dikatakan penulisan judul film pada poster ini memiliki clarity yang berbeda, sehingga dapat menarik perhatian.

Poster merupakan media komunikasi yang sejatinya dibuat untuk menarik perhatian para calon penonton, untuk memilih film yang menarik untuk ditonton. Elemen visual pada poster memiliki peran yang besar dalam menyajikan visualisasi yang dapat menarik perhatian terlebih pada penulisan judulnya. Pada penelitian ini lebih memfokuskan kepada elemen visual penulisan judul film, sebagai unsur pendukung elemen visual pada poster. Karena pemilihan jenis font yang akan digunakan bukan perkara yang mudah. Merangkai huruf dalam sebuah kalimat agar menghasilkan kalimat yang memiliki makna, serta mampu untuk memberikan pesan dan kesan dalam bentuk visual.

\section{SIMPULAN}

Elemen-elemen visual pada poster merupakan bagian yang sangat penting dalam menunjang keberhasilan suatu proses komunikasi. Karena poster sebagai media komunikasi harus mampu menyampaikan informasi atau pesan kepada audiens. Pada poster film, merupakan karya yang di dalamnya termasuk dalam elemen promosi, yang memiliki tujuan mempromosikan film, menarik perhatian sekaligus menggiring konsumen untuk menonton film.

Elemen visual penulisan judul, pemilihan huruf, dan tanda baca yang terdapat pada poster film $\operatorname{cin}(\mathrm{T}) \mathrm{a}$ merupakan sesuatu yang unik, dengan menggunakan tanda buka kurung, dan penulisan kapital pada huruf T. Jika huruf $\mathrm{T}$ dihilangkan maka akan terbaca cina, dan jika huruf $\mathrm{T}$ diikut sertakan akan terbaca cinta. Satu kata bisa menjadi dua makna.

Huruf $\mathrm{T}$ tersebut memiliki makna Tuhan. Dan film cin(T)a, pesan yang terkandung di dalam judul film tersebut, memberi arti Tuhan itu merupakan director dalam kehidupan kita. Semua ketentuannya sudah pasti baik. Dan sebagai makhluk ciptaanNya rasa cinta kita terhadap makhluk tidak boleh lebih besar dari rasa cinta kita kepada Tuhan.

\section{REFERENSI}

Baksin, A. (2003). Membuat Film indie Itu Gampang. Bandung: Katarsis

Sudjana, N. dan Rivai, A. (2010). Media Pengajaran. Bandung : Sinar Baru Algensindo.

Sudiana. D. (2001). klomedia. Bandung :rumah produksi dendi Sudiana.

Pedoman Umum Ejaan Bahasa Indonesia Yang Disempurnakan.

Ekawardhani, Y. A., Natagracia, G., (2012). "Kajian Prinsip Pokok Tipografi (legibility, readibility, visibility, dan clarity) pada Poster Film Beranak dalam Kubur The Movie dan Jelangkung," 
VISUALITA, vol. 4, no. 1, pp. 8799.

Sihombing, D. (2015) Tipografi Dalam Desain Grafis, Jakarta: PT. Gramedia Pustaka Utama.

Sastrosoediro, M. (1998). Poster Layanan Masyarakat dan Generasi muda. Yogyakarta: Indonesia Cerdas. http://luvita09.blogspot.co.id/2011/02/si nopsis-film-cinta.html

http://ajirenji.blogspot.co.id/2009/12/no minasi-festival-film-indonesia2009.html 